
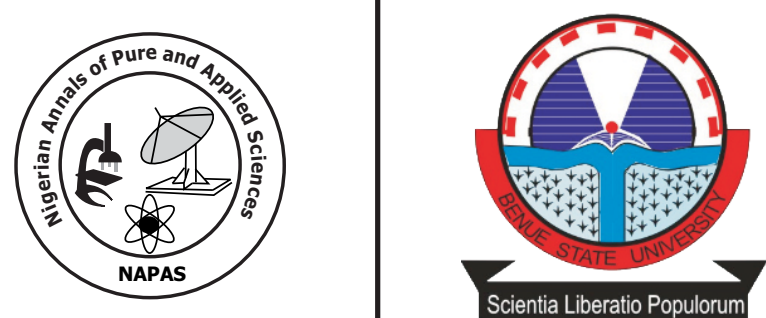

\title{
Morphology, Protein Profile and the Level of Infestation of Bedbugs (Hempitera: Cimicidae) in the Halls of Residence of a Higher Institution in Lagos.
}

\author{
Kemabonta, K. A. and Ajiboye, M. 0 \\ Department of Zoology, \\ University of Lagos, Lagos State, Nigeria \\ *Correspondence:ajiboye.maryam@yahoo.com
}

\begin{abstract}
\end{abstract}
Morphology, protein profile and the level of Bedbug infestations were carried out at a University in Lagos, Nigeria after an outcry of high infestation by the students in halls of residence. Three bedbugswere each collected from nine halls of residence for morphological characterization of adults and to carry out protein profile analysis usingSodium Dodecyl Sulfate Polyacrylamide Gel Electrophoresis (SDS-PAGE) and Coomassie staining method. Level of infestation of Bedbugs was carried out in two female halls A and Busing blood smeared on the walls. All bedbugs found were Cimex hemipterus. 29.8\% of the rooms in Hall Bhad no bedbug infestation, $23.9 \%, 20.2 \%, 15.4 \%$ and $10.6 \%$ had low, average, high and very high levels of bedbug infestation respectively while in A hall, it was $21.4 \%, 30.5 \%, 24.4 \%, 14.5 \%$ and $9.2 \%$ respectively. In A hall, $4.6 \%, 16.8 \%$ and $0.8 \%$ had one, two and three out of the four mattresses in the room infested with bedbugs respectively while $56.5 \%$ had all the four mattresses infested with bedbugs. In B hall, 1.6\%, 16.0\% and 0\% had one, two and three mattresses infested with bedbugs respectively while the remaining $52.7 \%$ had all the four mattresses in the room infested with bedbugs. There was a significant relationship between the level of infestation and the number of mattresses infested in each hall $(\mathrm{P}<0.01)$. The protein profile analysis of bedbugs did not show the protein bands clearly because of the low soluble protein content of Cimex hemipterus and the detection limit of Coomassie stain.

Key words: Bedbug, survey, Protein Profile, Morphology, Cimex hemipterus 


\section{Introduction}

Bedbugs (Hemiptera, Cimicidae), are small, gregarious, crawling insects which feed on human blood by piercing the skin. They are most commonly found on mattresses, particularly along the stitched edges where there are folds, which provide protection to them. They can also be found in bed frames, behind bed heads, in bed side furniture and floor joints, carpet edges, air conditioning ducts, light fittings, picture frames, behind wall paper and wall fan, iron bunks with springs, alongside of boxes and other cracks and crevices. They seek out blood meals from humans, usually at night and are attracted to body heat and the carbon dioxide exhaled by humans.

They can be distinguished from other Hemipterans by being flightless, exclusive blood feeders, oval and flattened in shape (Carver et al., 1991). When unfed, they are pale yellow or brown in colour, but after a full blood meal become reddish brown. The average length and width of the adult bedbugs are 5.5 and $2.5 \mathrm{~mm}$ respectively (Khan and Rahman, 2012).

The life cycle of a Bedbug consists of an egg, five nymphal stages and an adult. The nymphs are miniature versions of the adults in general appearance.Pathogens have been detected in bedbugs but they are not known to transmit any communicable disease. Cutaneous reactions may occur and can start out as small macular lesions that can develop into distinctive wheals of around $5 \mathrm{~cm}$ in diameter, which are accompanied by intense itching and this may result in blemish on the skin (Doggett et al., 2012). Bedbugs also cause nuisance due to their activities at night thereby causing sleepless nights to their hosts which could lead to stress.

There are 3 human bedbug speciesLeptocimex boueti which are found on bats and man locally in West Africa, throughout the Old and New World tropics; Cimex hemipterus $(\mathrm{F})$ found attacking man, chickens, and rarely bats and Cimex lectularius L. which is associated with man, bats, chickens, and occasionally other domesticated animals (Usinger, 1966). These three species have made transition from bats as primary host to humans. The two species that affect humans ( $C$. hemipterus and $C$. lectularius) can be differentiated using different morphological features. These two species are similar by having the same morphological features with slight differences. The most distinguishing difference is the slight difference in their pronotum. The pronotum of Cimex lectularius is wider than that of Cimex hemipterus because of an upturned lateral flange on the margin of the pronotum on the thorax of Cimex lectularius which is absent in Cimex hemipterus (Usinger, 1966).

The morphology of bedbugs need to be understood because this pest is a challenging and re-emerging indoor insect pest. Due to the global resurgence and pesticide resistance, bedbugs have now gotten to the level of being a major urban insect pest. To devise appropriate control measures and to avoid indiscriminate use of pesticides, bedbugs need to be identified in order to determine the species posing threat on humans and their level of infestation need to be determined in order to ensure proper application of pesticides.

\section{Materials and methods}

Morphology of Bedbugs: The morphological features of Bedbugs were observed using a digital microscope and they were viewed at $60 \mathrm{X}$ and $120 \mathrm{X}$ magnifications depending on the part viewed. Identification was done based on the keys found in Usinger 1966.

Life stages of Bedbugs: The life stages of bedbugs were identified from the samples collected in the hostel using the keys in Usinger 1966. The images of the egg (unhatched and hatched), the five nymphal stages and the adults were taken using the same digital microscope.

\section{Morphological Characterization of Bedbugs:} Bedbugs were identified using the same digital microscope. The pronotum which is the most distinguishing feature used to identify the two bedbugs species (Cimex hemipterus and Cimex lectularius) that parasitize man was observed in some of the samples gotten from different rooms in nine halls. The dorsal and ventral sides of the Bedbug pronotum were observed to get a distinct image of the pronotum because the projecting edge of some were not very clear dorsally.

\section{Level of Infestation of Bedbugs in two female halls (A and B)}

A survey was carried out to determine the prevalence of bedbugs in these halls. All the rooms in these halls were inspected by checking the blood smear of bedbugs killed on the walls of each room. The level of infestation was determined using an approximate of the number of blood smeared on the walls of the rooms.

Each room has two bunks with each located by the side of the wall, some rooms had the walls of the two bunks stained with blood smear which shows that the four mattresses were infested while some had one side of the wall stained with blood smear, it shows that just the two beds on that bunk were infested. 


\section{Keys used:}

Walls with no blood stain were classified as none, Blood smear less than 5 on the walls were classified as low.

Blood smear between 6 and 15 on the walls were classified as average while

Blood smear between 15 and 25 were classified as high and those above 25 were classified as very high

\section{Protein Profile of Bedbugs Using Sodium Dodecyl Sulfate Polyacrylamide Gel Electrophoresis (SDS-PAGE) and Coomassie Brilliant Blue (R-250) Staining Method Gel Preparation and Loading:}

SDS-PAGE is a common method of separating proteins by electrophoresis. The Discontinuous (Laemmli) denaturing SDS-PAGE and Coomassie staining method was used for this work. Fresh 10\% Ammonium persulfate (APS) solution was prepared in a microfuge tube, the gel casting apparatus (Vertical Gel Electrophoresis apparatus) was assembled. Two clean glass plates lined with spacers were placed in the apparatus and it was tightly fitted to prevent leakages of the gel solution.

Separating gel of $12 \%$ acrylamide concentration was prepared using $6.0 \mathrm{ml}$ of $30 \%$ acrylamide/ $0.8 \%$ bisacrylamide, $5.3 \mathrm{ml}$ of $\mathrm{H}_{2} \mathrm{O}$,

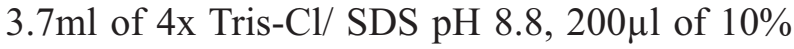
Ammonium persulfate and $10 \mu 1$ TEMED. The apparatus is then loaded with $4.5 \mathrm{ml}$ of the separating gel solution which is poured in between the two glass plates. The separating gel is then topped with approximately $1 \mathrm{ml}$ of isopropyl alcohol to isolate the polymerization of the gel from oxygen. After polymerization, the isopropyl alcohol was poured off and rinsed with distilled water and dried with Whatman paper and the comb was inserted for the stacking gel.

The stacking gel of $5 \%$ acrylamide preparation was prepared using $3.0 \mathrm{ml} \mathrm{H}_{2} \mathrm{O}, 1.3 \mathrm{ml}$ of $4 \mathrm{x}$ Tris-Cl/ SDS pH6.8, $0.9 \mathrm{ml}$ of $30 \%$ acrylamide/ $0.8 \%$ bisacrylamide, $80 \mu 110 \%$ APS and $5 \mu 1 \mathrm{TEMED}$. The stacking gel is loaded on the separating gel carefully to avoid introducing air bubbles around the comb. The stacking gel was allowed to polymerize completely for about 45 minutes before removing the comb.

\section{Sample Preparation and Loading}

Each protein sample (Bedbug) was kept in an eppendorf tube and weighed, it was diluted with $15 \mu \mathrm{l}$ of sample buffer and then boiled for 10 minutes in heat-block to denature the proteins. The samples were later kept on ice for 5 minutes and spinned in centrifuge for 15 minutes at
15,000RPM. The resulting solution was the protein sample that was loaded for Electrophoresis.

The glass and gel sandwich was clipped to the electrophoresis apparatus and the comb was carefully removed from the gel to avoid damaging the wells. The top of the apparatus was filled with 1x SDS Electrophoresis Buffer. The wells were rinsed out with buffer using a micropipette. $10 \mu 1$ of each sample was carefully loaded into the bottom of each well using a flat-tipped pipette tip. The protein ladder which is a standard was also placed in a well to help analyze the samples. The apparatus filled with 1x SDS electrophoresis buffer was connected to the power supply to perform electrophoresis. The power supply was turned off and the gel sandwich was removed when the dye reached the bottom of the separating gel. The sandwich was carefully opened by using one of the spacers to pry the glass plates apart. The stacking gel was gently cut off while the separating gel was placed in a small plastic container for staining. The gel was covered with fixing solution and shook gently for 15 minutes. Coomassie staining was used to analyze the gel, the fixer was poured off and the gel was covered with staining solution for about 2 hours. The staining solution was poured off and distained for about 2 hours.

\section{Results}

\section{Morphology of bedbugs (Cimex hemipterus)}

The head consist of the mouthpart, antenna and the eye. Dorsally, the parts visible in the head are the Clypeus, Eyes and the Antenna. Bedbugs have a pair of Eyes which protrudes from the side of the head and it is a knob-like structure. The Clypeus is found at the anterior part of the head region which extends shortly (downward) towards the dorsal side of the head. Bedbugs have a pair of antennae with each antenna located at the side of the head. The antennas are divided into four segments.

Bedbug Thorax has three segments like every other insects namely; prothorax, mesothorax and metathorax. The prothorax which is wider than the mesothorax and the metathorax and it is just beneath the head with a little bit curved at the edge. Dorsally, the prothorax is known as Pronotum.The mesothorax is underneath the prothorax where the hemelytral pad (reduced forewings) is found. Bedbugs (Cimexspecies) are wingless and their wings have been modified into the hemelytral pad. The mesothoracic notum also known as scutellum is $\mathrm{V}$ shaped which extends from the mesothoracic segment and terminates in between the hemelytral 
pad above the metathoracic segment.

Each thoracic segment has a pair of legs. A leg is divided into coxa which attach to the thoracic segment, femur, tibia, tarsus and two tarsal claws. The abdomen has 11 segments with the second to ninth segments being visible dorsally.

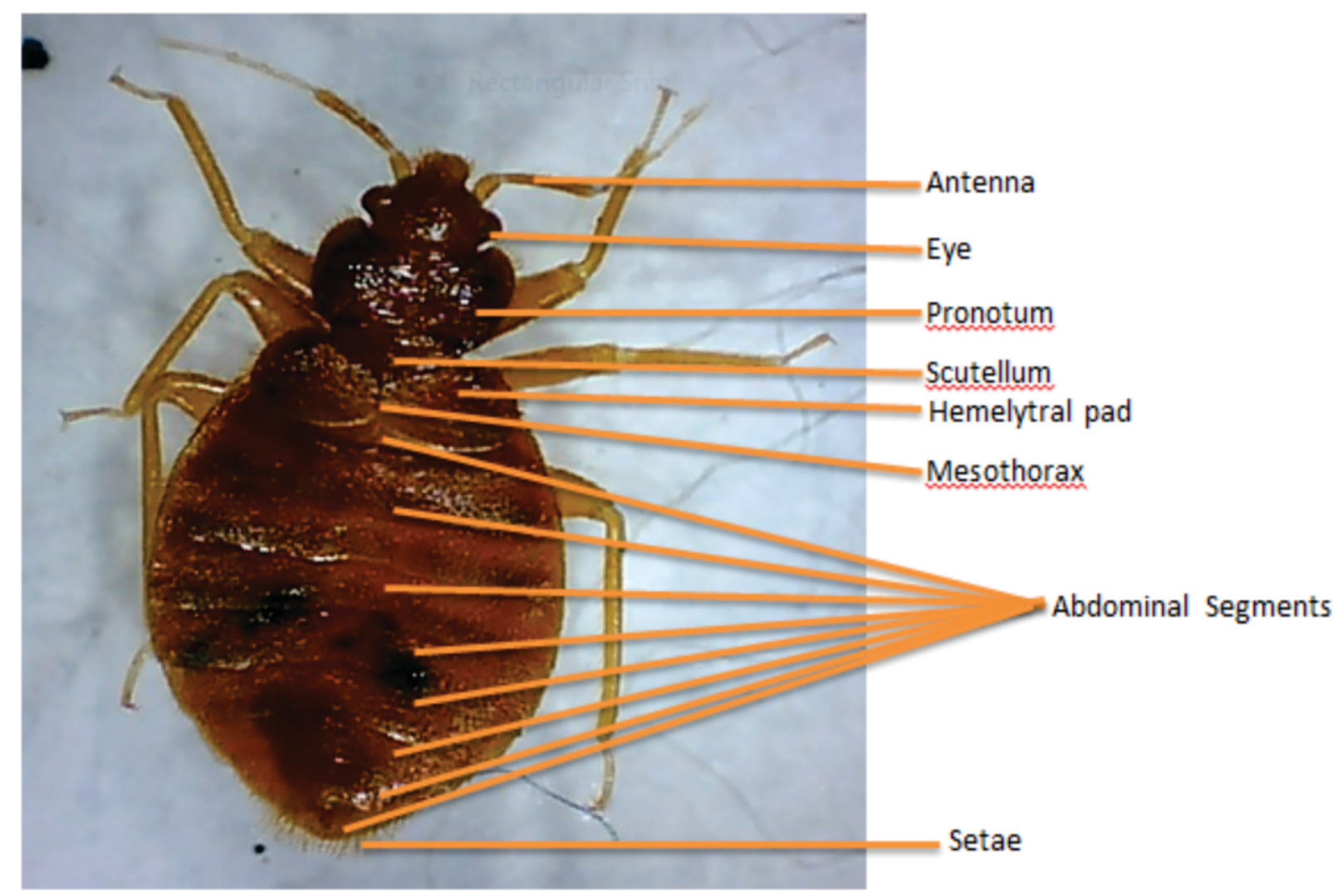

Plate 1: Dorsal view of a C. hemipterus X60

\section{Morphological characterization of cimex hemipterus}

In all the observed species, the pronotum is not wideand its projecting edge is not upturned like that of Cimex lectularius, this shows that the species found were Cimex hemipterus.

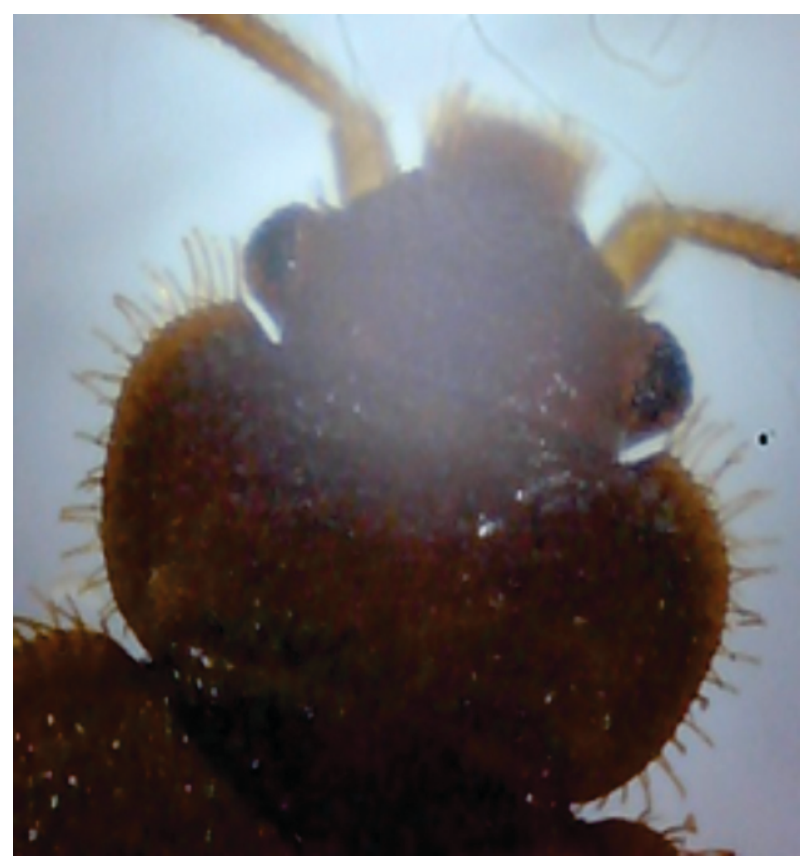

Plate 2: Pronotum of Cimex hemipterus found in one of the hallsX120

\section{Life stages of bedbugs}

Bedbug eggs are tiny, whitish or creamy in colour. The body of the eggs is always sticky which makes them attached to the surface in which they are laid. During hatching, the operculum of the eggs open and the bedbugs come out of its shell leaving the operculum open. The newly hatched bedbug (first instar nymph) is tiny and lighter in colour. Bedbugs pass through five nymphal stages and each stage molt into the subsequent stage by shedding its exuvia. They become bigger and darker in colour as they molt into subsequent stages. The fifth instar nymph molt to become a male or female adult bedbug.

Male bedbug can be differentiated from the female by comparing the tip of their abdomen which is rounder in female and pointed in male. When fed, the abdomen of bedbugs expands and the "hunger folds" are exposed. 


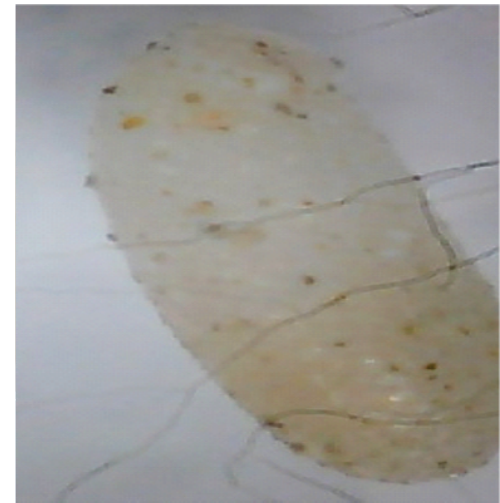

Plate 3A: Egg Before Hatching $\mathrm{X} 120$

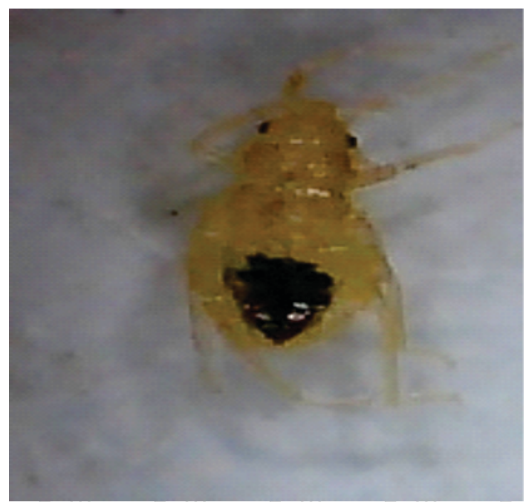

Plate3D: Second Instar Nymph X60

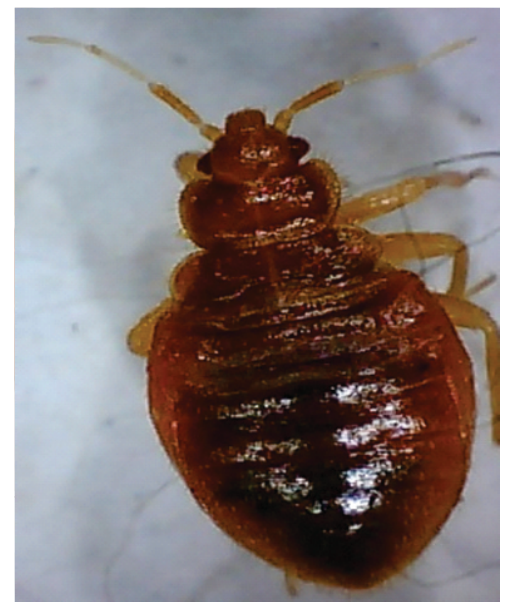

Plate 3G:Fifth Instar Nymph X60

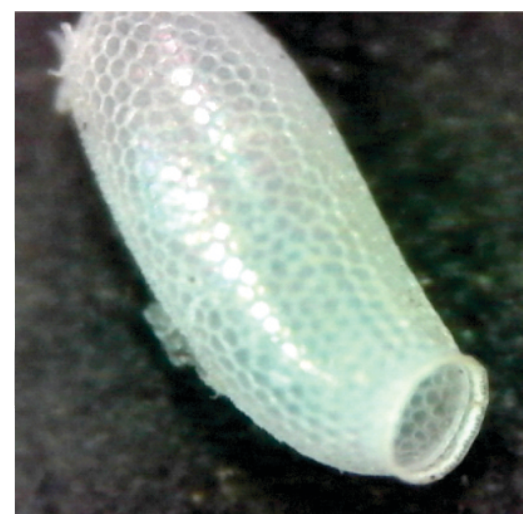

Plate 3B: Egg after hatching X120

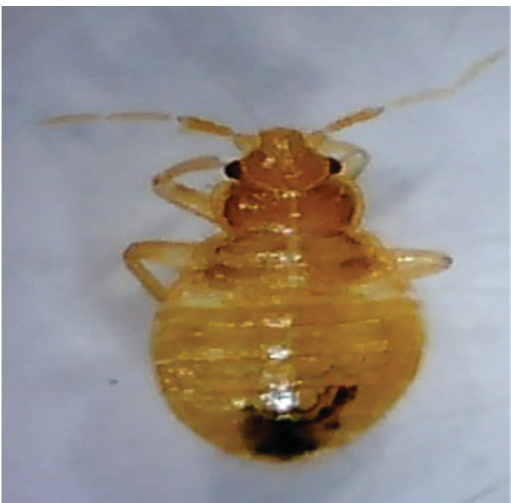

Plate 3E: Third Instar Nymph $\mathrm{X} 60$

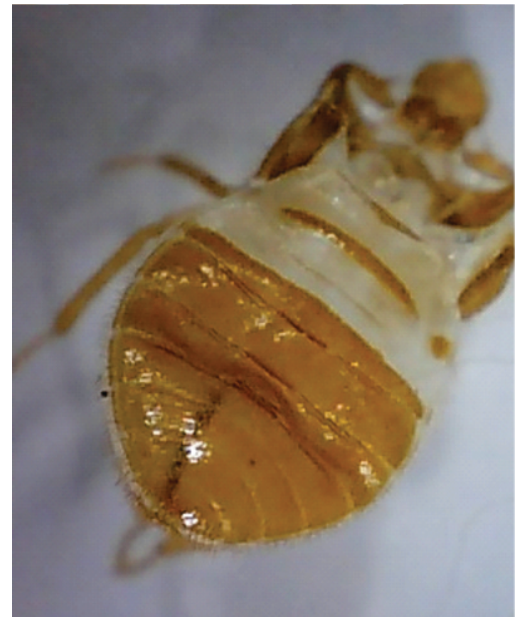

Plate 3H: Fifth Instar Exuvia X60

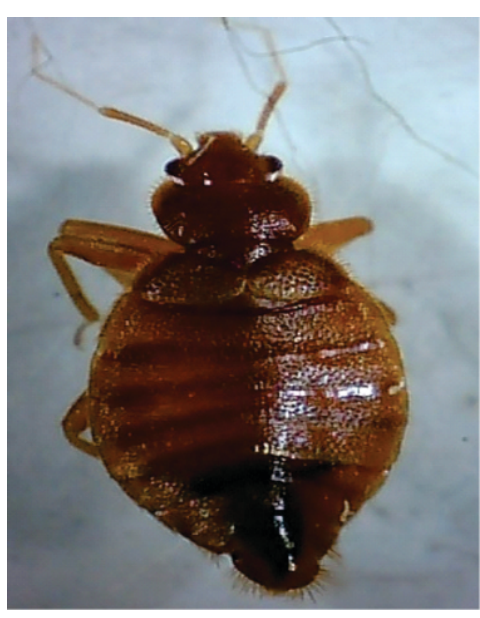

Plate 3C: First Instar Nymph X 60

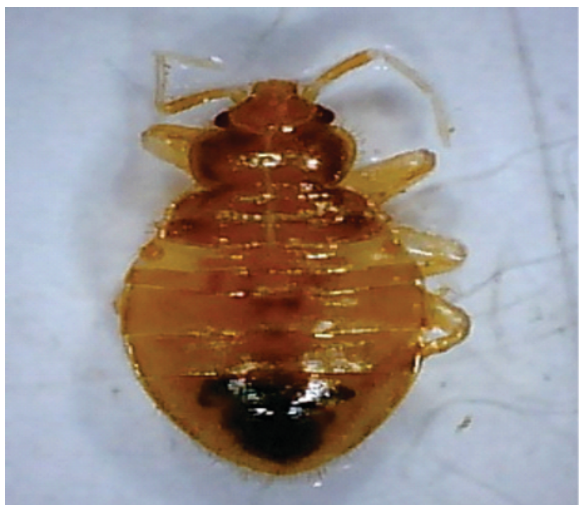

Plate 3F: Fourth Instar Nymph X60

Plate 3I: Male Bedbug X60 


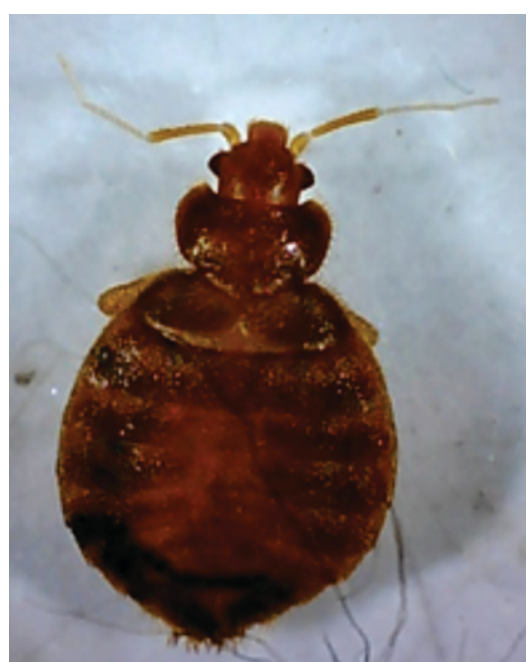

Plate 3J: Female Bedbug X60

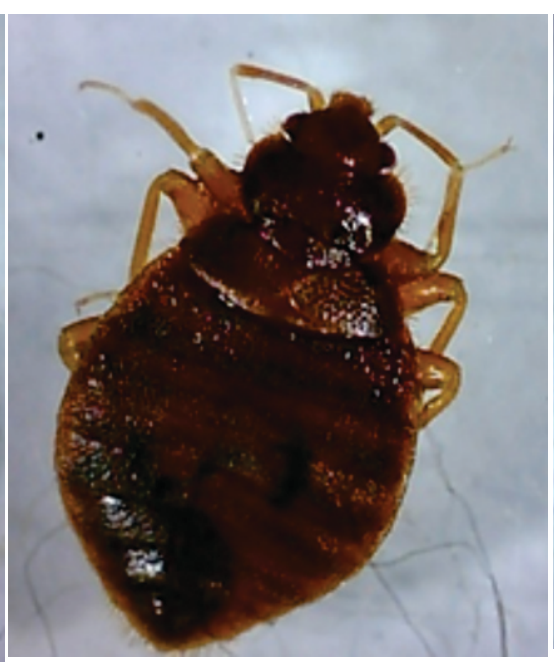

Plate 3K: Unfed Bedbug X60

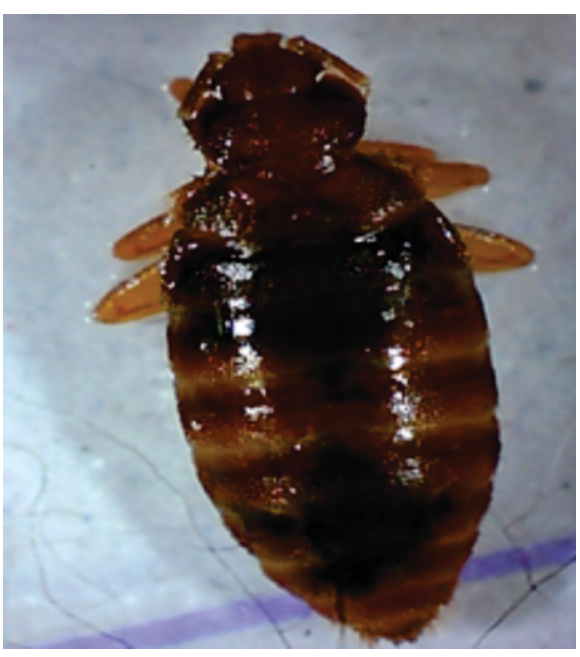

Plate 3L: Fully engorged Bedbug exposing the hunger folds X60

Life Stages of Bedbugs (Cimex Hemipterus) (Plate 3A- G), Exuvia (Plate 3H), Male and Female Bedbugs (Plate 3I-J), Unfed and Fed Bedbugs (Plate 3K-L)

Infestation of bedbugs in A and B Halls USING Blood smeared on the walls.

\section{Hall A}

Out of 131 rooms inspected in Hall A, 21.4\% had no bedbug infestation, $30.5 \%$ had low level of infestation, 24.4\% had average level of infestation, $14.5 \%$ had high level of infestation and the remaining $9.2 \%$ had very high level of infestation (Table. 1).

Table 1: Level of Infestation in hall A

\begin{tabular}{lll}
\hline Level of Infestation & Frequency & Percentage (\%) \\
\hline None & 28 & 21.4 \\
Low & 40 & 30.5 \\
Average & 32 & 24.4 \\
High & 19 & 14.5 \\
Very High & 12 & 9.2 \\
Total & 131 & 100.0 \\
\hline
\end{tabular}

Results on number of mattresses infested in each room showed that $21.4 \%$ had no mattress infested; $4.6 \%$ had only one mattress, $16.8 \%$ had two, $0.8 \%$ had three mattresses infested while the remaining $56.5 \%$ had all the four mattresses infested with bedbugs in a room (Table: 2 ).

There was a significant relationship between the number of mattresses infested and the level of infestation in each room in hall $\mathrm{A}\left(\mathrm{F}_{4,126}=31.646 ; \mathrm{P}\right.$ $<0.01)$

Table 2: Number of mattresses infested in each room in hall $\mathrm{A}$

\begin{tabular}{lll}
\hline Number of mattresses affected & Frequency & Percentage (\%) \\
\hline 0 & 28 & 21.4 \\
1 & 6 & 4.6 \\
2 & 22 & 16.8 \\
3 & 1 & 0.8 \\
4 & 74 & 56.5 \\
Total & 131 & 100.0 \\
\hline
\end{tabular}

\section{HALLB}

Table 3 shows the level of infestation of bedbugs in hall B. Out of the 188 rooms inspected $29.8 \%$ had no bedbug infestation, $23.9 \%, 20.2 \%$, $15.4 \%$ and $10.6 \%$ had low, medium, high and very high levels of bedbug infestation respectively. Moreover, 29.8, 1.6, 16, 0, and 52.7\% had no infestation, 1, 2, 3, and all 4 mattresses respectively per room, infested with bedbugs (Table 4).

There was a significant relationship between the number of mattresses infested and the level of infestation in each room in Hall B $\left(\mathrm{F}_{4,183}=228.030, \mathrm{P}\right.$ $<0.01)$ 
Table 3: Level of infestation in Hall B

\begin{tabular}{lll}
\hline Level of infestation & Frequency & Percentage (\%) \\
\hline None & 56 & 29.8 \\
Low & 45 & 23.9 \\
Average & 38 & 20.2 \\
High & 29 & 15.4 \\
Very High & 20 & 10.6 \\
Total & 188 & 100.0 \\
\hline
\end{tabular}

Table 4: Number of Mattresses infested in each room in Hall B

\begin{tabular}{lll}
\hline Number of mattresses infested & Number of rooms & Percentage (\%) \\
\hline 0 & 56 & 29.8 \\
1 & 3 & 1.6 \\
2 & 30 & 16.0 \\
3 & 0 & 0.0 \\
4 & 99 & 52.7 \\
Total & 188 & 100.0 \\
\hline
\end{tabular}

Level of infestation in each hall (Plate 4A-H)Infestation Level

Hall A

LOW

Average
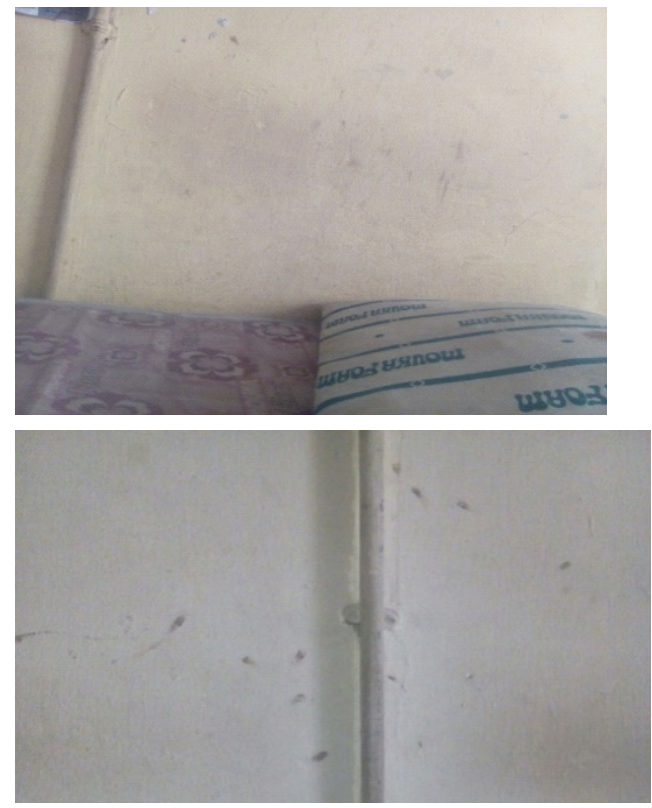

High

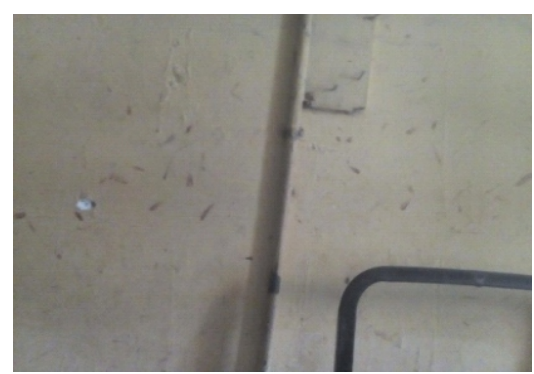

Hall B
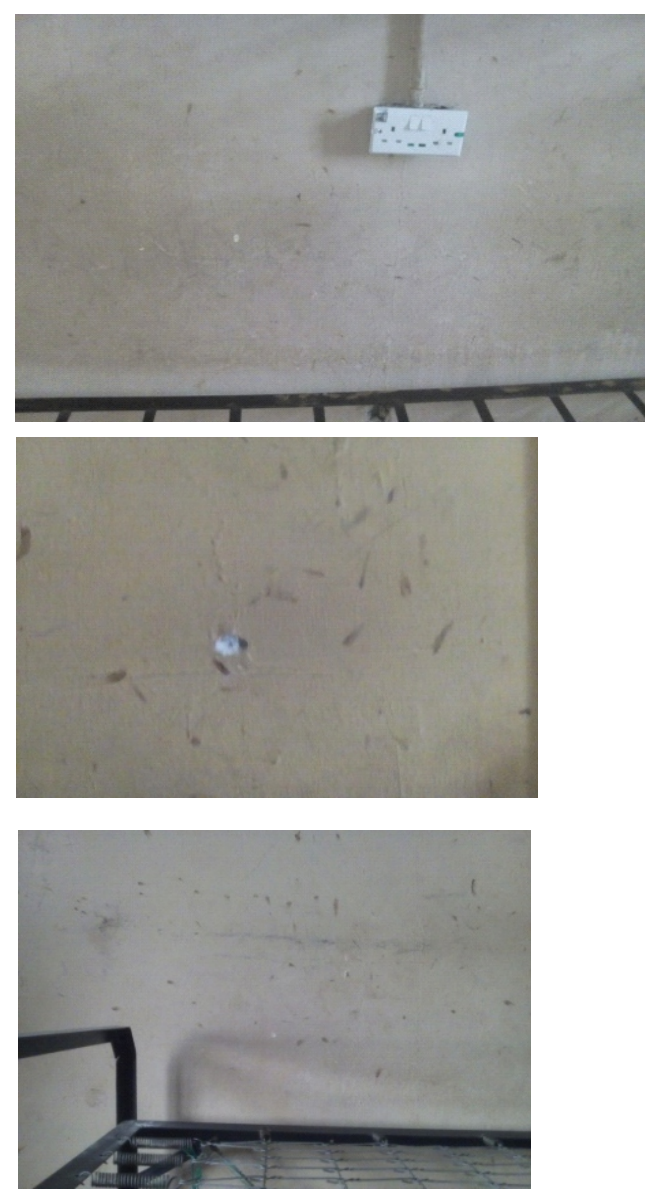

\section{Very High}
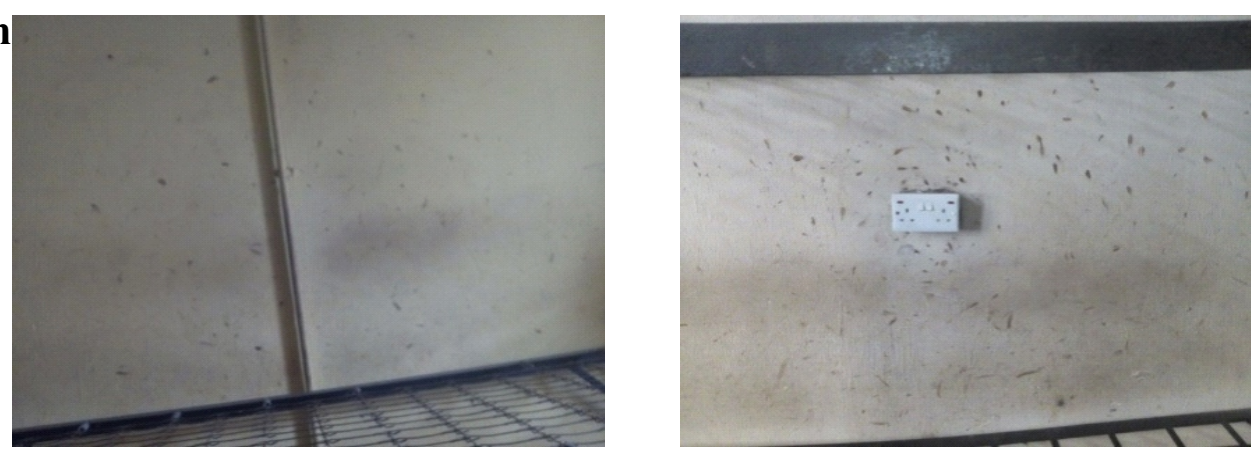


\section{Protein profile of bedbugs samples gotten from nine halls}

The result of the protein profile of bedbugs carried out using Sodium Dodecyl Sulfate Polyacrylamide Gel Electrophoresis (SDS-PAGE)

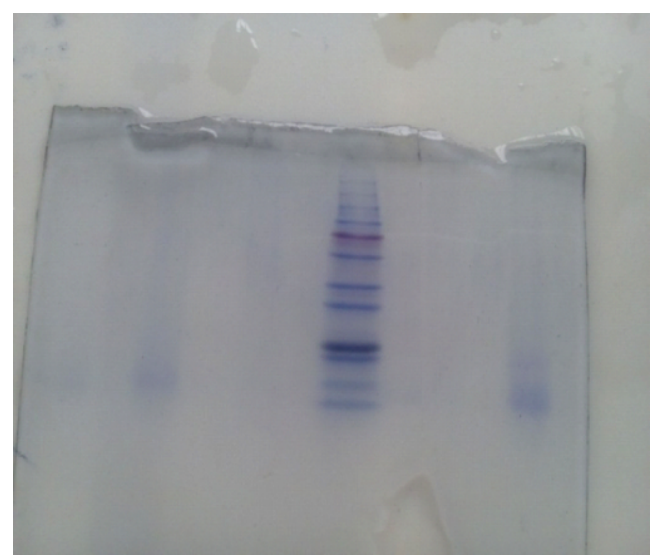

Plate 5a: Protein profile of bedbug sample 1 - 10 on a Gel with the protein ladder in the middle

\section{Discussion}

This study investigated the morphology, protein profile, and levels of bedbug infestation at nine halls of Residence in a higher institution in Lagos. Morphological characterization helps to determine if the species found in all hostels are the same while protein profile was used to check if they were from the same origin and this can tell if these bedbugs were transferred from one hall to the other.

The morphological characterization of bedbug samples gotten from the hostels revealed that they are all Cimex hemipterus (the tropical bedbug). Tropical bedbugs (Cimex hemipterus) are found in tropical climate and Nigeria is a tropical country. According to Doggett et al., (2011), Cimex hemipterus are tropicopolitan. Johnson (1942) also reported that Cimex hemipterus was less resistant to extremes of cold temperature with $10^{\circ} \mathrm{C}$ being its lower limit and without doubt, this has limited its geographical distribution to the tropics. The maps of Mellanby (1935) and Geisthardt (1937) showed that Cimex hemipterus are almost restricted to the tropics and it hardly extends beyond tropics. Khan and Rahman (2012) also bred Cimex hemipterus at room temperature of $28 \pm 4^{0} \mathrm{C}$ in the laborartory. Omori (1941) found that Cimex hemipterus clustered in the range from 32 to $33^{\circ} \mathrm{C}$.

The survey carried out in hall A and hall B showed that most rooms were infested even though the level of infestation and the number of mattresses affected in each room varied. The result also showed that there is a highly significant relationship between the level of infestation and and Coomassie staining method did not show clear protein bands due to the low soluble protein content of the bedbugs. Coomassie Blue Stain R-250 can only detect up to a certain quantity of protein which is approximately 100 Nanogram.

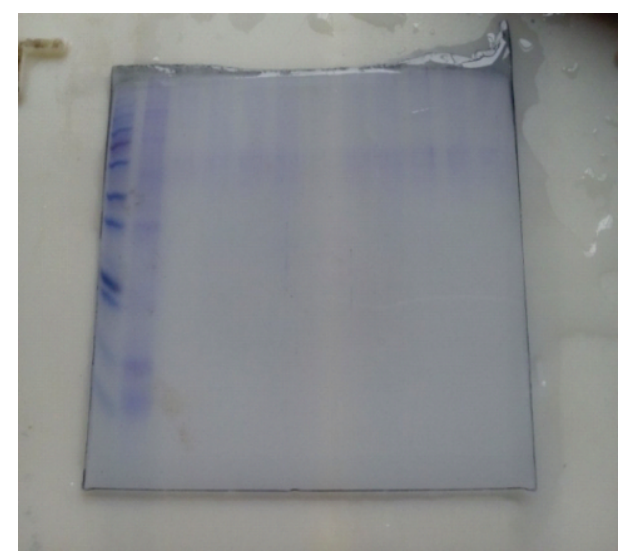

Plate 5b: Protein profile of bedbug sample 11 20 on a Gel with the protein ladder at the left side.

the number of mattresses affected in each hall. This study shows the habitat and the prevalence of bedbugs in the halls of residence. Bedbugs (Cimicidae) are cryptic in nature (Doggett et al, 2004) and are mostly active at night but they are not completely nocturnal as they can be found very active during the day when there is a high level of infestation and this was observed during collection from different halls.

Bedbugs were gotten from the places where they seek refuge during the day and these places are within the springs of iron bunks, along the seams of mattresses, inside and behind wall sockets and wires, and other cracks and crevices around the wardrobe and walls of the rooms. Their harbourages are found very close to their host because they are crawling insects and cannot fly to locate their host. The fact that they are haematophagous makes them available anywhere they find their suitable host because they need blood for survival, development as well as egg and sperm production. It might be a clean or filthy environment but they are mostly associated with filthy environment and their presence can make a clean environment filthy due to their frass, exuvia, egg shell, dead ones, nymphs and adults.

This work investigated the protein profile of Cimex hemipterus in order to determine if the identified bedbugs species are from the same origin by comparing their protein bands. Electrophoresed proteins exist as concentrated bands embedded within each lane of the porous Polyacrylamide gel matrix. In this work, Classiscal Brilliant Blue (R-250) was used to stain the gel after carrying out electrophoresis. This 
technique is an easy and a very reliable quantitative staining method but it is less sensitive and its has a detection limit of about 100Nanogram (Weiss et al., 2009) and this makes the visualization of low soluble protein contents difficult. The result showed that Cimex hemipterus has low soluble protein content which could not be seen clearly if Coomassie stain is used.

\section{Conclusion and Recommendations}

The results from this work revealed that the halls were infested with Cimex hemipterus (tropical bedbug). The level of infestation in the halls should be investigated often in order to control this pest effectively. For the sake of further research, due to the low soluble protein content of Cimex hemipterus and the detection limit of Coomassie staining (R-250), a very sensitive staining technique (e.g. Silver staining) should be used for the protein profile of Cimex hemipterus. Molecular studies can also be used to classify bedbugs species and to check how the species are related in order to determine if they are from the same origin.

\section{References}

Carver, M., Gross, G. F. and Woodward, T. E. (1991). Hempitera: The insects of Australia, 2nd edition, volume 1 Melbourne University Press, Carlton, Australia. pp 429-509

Doggett, S. L., Dwyer, D. E., Penas, P. F. and Russell, R. C. (2012). Bed Bugs: Clinical Relevance and Control Options. Clinical Microbiology Review 25(1): 164-192.

Doggett, S. L., Geary, M. J. and Russell, R. C. (2004). The resurgence of bed bugs in Australia, with notes on their ecology and control. Environmental Health4:30-38

Doggett, S. L., Orton, C. J., Lilly, D. G. and Russell, R. C. (2011). Bed bugs - a growing problem worldwide, Australian and international trends update and causes for concern, session 2A. Abstract, Australian Environmental Pest Managers Association NSW Conference 2011, Sydney, Australia.

Johnson, C. G. (1942). The ecology of the bedbug, Cimex lectularius L., in Britain. Journal of Hygiene. 41 (4) 345-461.

Khan, H. R and Rahman, M. M. (2012). Morphology and Biology of the Bedbug, Cimex hemipterus (Hemiptera: Cimicidae) in the laboratory. Dhaka University Journal of Biological Science 21 (2): 125-130.

Mellanby, K. (1935). A comparison of the physiology of the two species of bed-bug whichattack man. Parasitology 27: 111-22

Omori, N. (1941). Comparative studies on the ecology and physiology of common and tropical bed bugs, with special references to the reactions to temperature and moisture. Journal of the Formosan Medical Association60 (4) - 433: 555-729.

Usinger, R. L. (1966). Monograph of Cimicidae (Hemiptera -Heteroptera). Entomological Society of America, College Park, Maryland. Volume 7, $572 \mathrm{pp}$.

Weiss, W., Weiland, F. and Gorg, A. (2009). Protein detection and quantitation technologies for gel-based proteome analysis. Volume 564 of Methods in Molecular Biology, Humana Press, pp. 59-82. 